\title{
Conjugation, meiosis, and the osmotic stress response are regulated by Spc1 kinase through Atf1 transcription factor in fission yeast
}

\author{
Kazuhiro Shiozaki and Paul Russell ${ }^{1}$ \\ Departments of Molecular Biology and Cell Biology, The Scripps Research Institute, La Jolla, California 92037 USA
}

The stress-activated Wis1-Spc1 protein kinase cascade links mitotic control with environmental signals in Schizosaccharomyces pombe. Fission yeast spc1 $1^{-}$mutants are delayed in $\mathrm{G}_{2}$ during normal growth and undergo $G_{2}$ arrest when exposed to osmotic or oxidative stress. Here we report that Spc1 also has an important role in regulating sexual development in $S$. pombe. This discovery arose from the observation that Spc1 is activated in response to nitrogen limitation, a key signal that promotes conjugation in fission yeast. Mutant spc1 $1^{-}$cells are defective at arresting in $G_{1}$ during nitrogen starvation and exhibit a poor mating ability. These deficiencies correlate with a failure to induce transcription of $s t e 11^{+}$, a gene that encodes a transcription factor responsible for expression of various meiotic genes. Two genes, atf $1^{+}$and $a t f 21^{+}$, were cloned as multicopy suppressors of the spc1 ${ }^{-}$mating defect. Atf1 and Atf21 are bZIP transcription factors that are most closely related to human ATF-2/CRE-BP1. Spc1 is required for stress-induced phosphorylation of Atf1. Atf1 is required for induction of meiotic genes and stress-response genes, such as $g p d 1^{+}$and $p y p 2^{+}$, that are transcriptionally regulated by Spc1. atf1 $1^{-}$and $\operatorname{spc1^{-}}$ mutants are sensitive to osmotic stress and impaired for sexual development, showing that fission yeast uses a common pathway to respond to cytotoxic stress and nitrogen starvation. However, unlike spc1 ${ }^{-}$mutants, atf1 $1^{-}$cells have no mitotic cell-cycle defect, indicating that the stress response pathway bifurcates at Spc1 to regulate independently meiosis and mitosis.

[Key Words: ATF-2; meiosis; Schizosaccharomyces pombe; stress-activated MAP kinase]

Received May 2, 1996; revised version accepted July 23, 1996.

Studies of Schizosaccharomyces pombe have played an instrumental role in uncovering how eukaryotic cells regulate the initiation of mitosis. $\mathrm{Cdc} 2$, the cyclin-dependent kinase that is the focus of this control, is maintained in an inhibited state during $S$ and $G_{2}$ attributable to phosphorylation of tyrosine-15 carried out by Weel and Mik1 kinases (Dunphy 1994). Cdc2 is activated by Cdc25 tyrosine phosphatase to bring about the onset of mitosis. A major aim of recent studies has been to discover how the mitotic control is linked to checkpoint mechanisms that monitor genome replication and integrity, but recently it has become apparent that fission yeast also links the mitotic control with changes in the extracellular environment that affect cell physiology. A key element of this signal transduction pathway is Spcl, a mitogen-activated protein (MAP) kinase homolog that is also known as Styl (Millar et al. 1995; Shiozaki and Russell 1995). At optimal growth conditions Spcl has a

'Corresponding author. basal activity that is important for determining the timing of mitosis, as shown by the fact that $s p c 1^{-}$cells are $\sim 20 \%$ elongated at division compared with wild type. A spc1- mutation causes $\mathrm{G}_{2}$ arrest in cells that have a partial loss of Cdc25 activity, confirming that Spcl activity affects the mitotic control (Millar et al. 1995; Shiozaki and Russell 1995).

Spcl becomes highly activated in response to various forms of cytotoxic stress, including high osmolarity, oxidative stress, and high temperature (Millar et al. 1995; Shiozaki and Russell 1995; Degols et al. 1996). Failure to activate Spcl during stress leads to $G_{2}$ arrest and cell death. Spcl is most closely related to a conserved family of stress-activated protein kinases that includes budding yeast Hoglp (Brewster et al. 1993), Xenopus Mpk2 (Rouse et al. 1994), murine p38 (Han et al. 1994), and human CSBP1 (Lee et al. 1994). These kinases have a Thr-Gly-Tyr sequence in the region of activating phosphorylations, whereas other members of the MAP kinase family have Thr-Glu-Tyr or Thr-Pro-Tyr at corresponding positions. The MAPK kinase homolog Wis1 (Warbrick and Fantes 1991) activates Spcl by phosphorylating 
the threonine and tyrosine residues of the Thr-Gly-Tyr motif (Shiozaki and Russell 1995). Inactivation of Spc1 is carried out by tyrosine-specific phosphatases Pypl and Pyp2 (Millar et al. 1995; Shiozaki and Russell 1995; Degols et al. 1996), unlike other MAP kinase phosphatases that dephosphorylate both the threonine and tyrosine residues (Alessi et al. 1993; Sun et al. 1993; Doi et al. 1994).

Recent studies have shown that $\mathrm{Spcl}$ is required for the stress-stimulated transcription of several stress response genes, including those encoding glycerol-3-phosphate dehydrogenase $\left(g p d 1^{+}\right)$and trehalose-6-phosphate synthase (tps $1^{+}$) (Degols et al. 1996). Activation of Spcl also leads to expression of the pyp2 ${ }^{+}$gene encoding one of tyrosine phosphatases that regulates Spcl negatively, indicating the existence of negative feedback loop to attenuate Spcl activity (Millar et al. 1995; Degols et al. 1996). Various forms of stress induce expression of these genes in a $s p c 1^{+}$-dependent manner. Budding yeast Hoglp also regulates stress-inducible genes such as CTT1, GPD1, and HSP12, although Hoglp is reported to be specifically responsive to osmotic stress (Albetyn et al. 1994; Schüller et al. 1994; Varela et al. 1995).

In addition to cytotoxic stress, Spcl is activated when cells are grown in a synthetic minimal medium (Shiozaki and Russell 1995), suggesting that the Spcl pathway might also be involved in sensing the nutritional environment. In this paper we extend this observation by showing that $\mathrm{Spcl}$ is activated in response to limitation of a specific nutrient, namely, nitrogen. This finding is important because nitrogen limitation induces a program of sexual development in fission yeast. This program involves secretion of mating pheromones and expression of mating pheromone receptors, followed by $\mathrm{G}_{1}$ arrest and conjugation between cells of opposite mating types (Egel 1989). Nitrogen starvation also stimulates the meiotic pathway, thus newly formed zygotes normally proceed directly to meiosis, with the end product being four spores enclosed in an ascus. Our findings suggest that activation of the Wis1-Spcl kinase cascade is important for sexual development, because $s p c 1^{-} \mathrm{mu}$ tants are severely defective at arresting in $G_{1}$ and inducing mating genes upon nitrogen starvation. Two multicopy suppressors of the $s p c 1^{-}$sterile phenotype have been isolated; atf1 $1^{+}$and atf $21^{+}$encode basic zipper (bZIP) transcription factors that are related most closely to human activating transcription factor 2 (ATF-2)/ cAMP response element (CRE)-BP1 binding protein. at $f 1^{-}$and $s p c 1^{-}$mutants share various phenotypes, including failure to respond to nitrogen starvation, osmosensitive growth, and a defect in expression of stressresponse genes. Atfl undergoes Spcl-dependent phosphorylation during stress. These results strongly suggest that Atfl is a downstream target of Spcl. However, unlike spc1- cells, atf1- cells do not show a $\mathrm{G}_{2}$ delay phenotype, indicating that $\mathrm{Spcl}$ phosphorylates another substrate to regulate mitosis. We propose that the WislSpcl signal transduction pathway links mitotic and meiotic controls with changes in the extracellular environment that affect cell physiology.

\section{Results}

Spc1 is activated in response to nitrogen starvation

To examine the activation state of Spcl after nitrogen starvation, we used a haploid $S$. pombe strain in which the single chromosomal copy of $s p c 1^{+}$was tagged with a sequence encoding two copies of the HA epitope and six consecutive histidine residues (Shiozaki and Russell 1995). This allowed us to purify Spcl using $\mathrm{Ni}^{2+}$-NTA beads and detect it using anti-HA antibodies. Cells growing exponentially in standard EMM2 minimal medium were collected and resuspended in EMM2 lacking nitrogen. Activation of $\mathrm{Spcl}$ was assessed by monitoring the level of activating tyrosine phosphorylation using antiphosphotyrosine antibodies. Spcl tyrosine phosphorylation increased within $0.5 \mathrm{hr}$ of nitrogen depletion and peaked at $\sim 1 \mathrm{hr}$, then decreased to the initial level by 2.5 hr (Fig. 1A). This result indicates that Spc1 undergoes transient activation upon nitrogen limitation.

\section{Activation of Spc1 upon nitrogen starvation is required for $G_{1}$ cell-cycle arrest and induction of ste $11^{+}$expression}

In cultures of homothallic wild-type cells, nitrogen starvation initiates a program of sexual development in which cells arrest in $G_{1}$, mate with partners of the op-

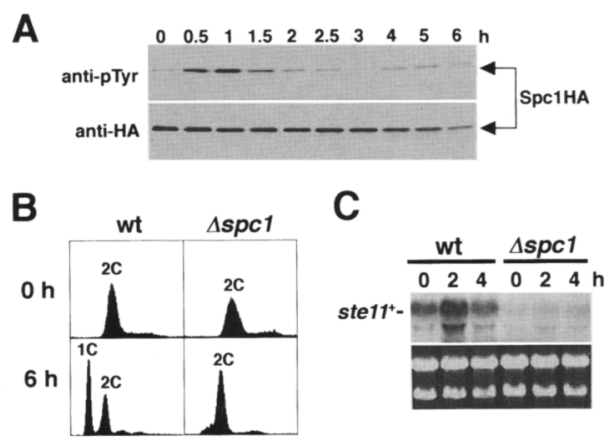

Figure 1. (A) Spcl undergoes activating tyrosine phosphorylation upon nitrogen starvation. Strain KS1376, in which the genomic copy of $s p c 1^{+}$encodes an epitope-tagged form of Spcl that has two copies of the HA epitope and six consecutive histidine residues at the carboxyl terminus, was grown to mid-log phase at $30^{\circ} \mathrm{C}$ in $\mathrm{EMM}_{2}$ medium and then cells were collected and resuspended into the same medium lacking a nitrogen source $\left(\mathrm{NH}_{4} \mathrm{Cl}\right)$. Spcl was purified using Ni-NTA-agarose beads and analyzed by immunoblotting with anti-phosphotyrosine (anti-pTyr) and anti-HA epitope antibodies. (B) FACScan analysis of DNA content in wild-type (wt; PR109) and $\Delta s p c 1$ (KS1366) strains after nitrogen starvation. Within $6 \mathrm{hr}$ of nitrogen deprivation a majority of wild-type cells arrested in $G_{1}$ with a $1 C$ DNA content, whereas only very few of the $\Delta s p c 1$ cells had a $1 C$ DNA content. (C) $\Delta s p c 1$ cells are defective in ste $11^{+}$expression. ste $11^{+}$mRNA in wild-type (PR109) and $\Delta$ spc1 (KS1366) strains was monitored at $2 \mathrm{hr}$ intervals after nitrogen starvation by Northern blotting (upper). Ethidium bromide staining of ribosomal RNA shown below indicates nearly equal loading of RNA in each lane. 
posite mating type, and then undergo meiosis. A key event in this program is the induction of ste $11^{+}$expression (Sugimoto et al. 1991). Stell is a transcription factor containing a high mobility group (HMG) motif that is required for transcription of mei2 ${ }^{+}$, a gene encoding an essential factor for the initiation of meiosis (Watanabe and Yamamoto 1994). Interestingly, $\mathrm{G}_{1}$ arrest and induction of ste $11^{+}$expression are not dependent on the presence of cells of opposite mating types, thus events that occur purely in response to nitrogen limitation can be distinguished from those that are dependent on a response to mating pheromones. The role of Spcl in these processes was evaluated by examining the behavior of a heterothallic $h^{-} \Delta s p c 1$ strain as it was starved of nitrogen. FACScan analysis of DNA content revealed that $\Delta s p c 1$ cells failed to arrest in $G_{1}$ after nitrogen starvation, whereas a large population of $G_{1}$ cells with a 1C DNA content was detected with wild-type cells (Fig. 1B). Expression of ste $11^{+}$mRNA was examined by Northern blotting. Under the experimental conditions used here, accumulation of ste11 ${ }^{+}$mRNA was observed $2 \mathrm{hr}$ after withdrawal of nitrogen from the growth medium and returned to the initial level by $4 \mathrm{hr}$ (Fig. 1C). On the other hand, in $\Delta s p c 1$ cells the amount of ste $11^{+}$mRNA was very low before and during nitrogen starvation (Fig. 1C), indicating that $\mathrm{Spcl}$ is important for expression of ste $11^{+}$. Defects in $\mathrm{G}_{1}$ arrest and ste $11^{+}$expression after nitrogen starvation were also observed with a $\Delta$ wis 1 strain (data not shown), suggesting that activation of the Wisl-Spcl pathway is important for cellular response to nitrogen limitation.

\section{Isolation of $\mathrm{spc1}^{-}$multicopy suppressors}

Our studies suggested that Spcl has a key early role in transmitting the nitrogen starvation signal that triggers the initiation of the sexual development. This proposal was supported by the observation that the efficiency of mating and sporulation was very low in a homothallic $h^{90}$ spc1-M13 strain (Fig. 2A). With the aim of identifying downstream elements of the Wis1-Spcl signal transduction pathway, we screened a $S$. pombe genomic DNA library and a cDNA expression library for plasmid suppressors of the $s p c 1^{-}$mating defect. Strain KS1440 $\left(h^{90}\right.$ leu1 ura4 spc-M13) was transformed with library DNA, and plasmids were recovered from sporulating colonies identified by iodine staining (see Materials and Methods). In addition to clones containing $s p c 1^{+}$, plasmids named $\mathrm{p} 2 \mathrm{~B}$ from the cDNA library and $\mathrm{p} 4 \mathrm{U}$ from the genomic library were found to rescue the sterility of the $s p c 1^{-}$strain (Fig. 2A). In comparison to vector controls, the $\mathrm{p} 2 \mathrm{~B}$ transformants had an enhanced ability to undergo $G_{1}$-arrest after nitrogen starvation (Fig. $2 B$ ) and grew much better in high-osmolarity medium (Fig. 2C). Plasmid p4U exhibited a similar ability to rescue the $\mathrm{G}_{1}$-arrest and osmosensitive defects of spc1-M13 cells (data not shown). Plasmid p2B contained a $1.2-\mathrm{kb}$ insert and sequence analysis indicated that the insert cDNA lacked the $5^{\prime}$ end (Fig. 3A). A full-length genomic clone was isolated from the genomic library by hybridization
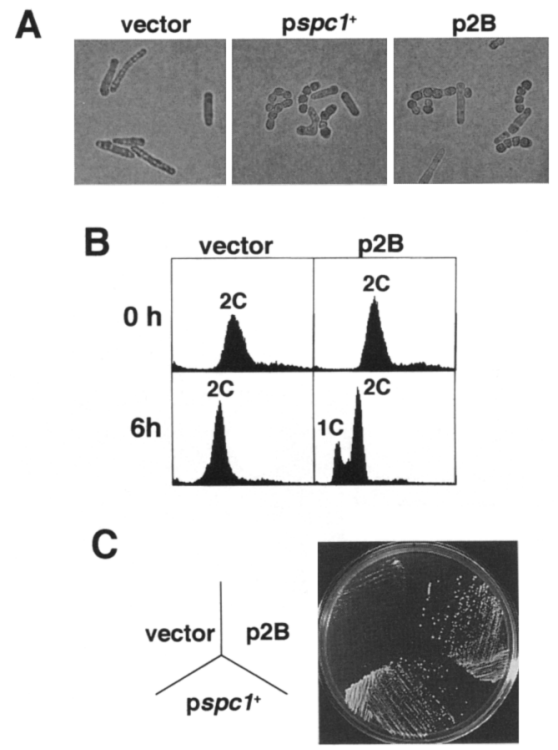

Figure 2. Multicopy suppressors of $s p c 1^{-}$. (A) Patches of $h^{90}$ spc1-M13 (KS1440) cells transformed with the negative control pREP3 (vector), pspc1 ${ }^{+}$, which carries $s p c 1^{+}$cDNA, or cDNA clone $\mathrm{p} 2 \mathrm{~B}$ were grown at $25^{\circ} \mathrm{C}$ for 4 days on an $\mathrm{EMM}_{2}$ agar plate supplemented with $1 \mu \mathrm{M}$ thiamine, and then streaked out for photographs. Plasmid pspc1 $1^{+}$and $\mathrm{p} 2 \mathrm{~B}$ transformants colonies contained a large number of asci with four spores, indicating rescue of the $s p c 1^{-}$mating defect, whereas the frequency of asci in the vector control transformants was $<1 \%$ in this experiment. $\{B\}$ cDNA p2B rescues partially the $G_{1}$ arrest defect of spc1- ${ }^{-}$cells after nitrogen starvation. spc1-M13 strain KS1147 was transformed by pREP3 vector alone or $\mathrm{p} 2 \mathrm{~B}$, and grown in $\mathrm{EMM}_{2}$ medium supplemented with $1 \mu \mathrm{M}$ thiamine. Cells were washed and reinoculated in the same medium without $\mathrm{NH}_{4} \mathrm{Cl}$ and their DNA content was examined by flow cytometry analysis after $6 \mathrm{hr}$ at $30^{\circ} \mathrm{C}$. (C) Suppression of high-osmolarity sensitive phenotype of $s p c 1^{-}$strain by cDNA p2B. Strain KS1147 transformed by $\mathrm{pREP} 3$ vector, $\mathrm{pspc} 1^{+}$, or $\mathrm{p} 2 \mathrm{~B}$ was streaked onto $\mathrm{EMM}_{2}$ medium with thiamine containing $1 \mathrm{M} \mathrm{KCl}$ and incubated for 4 days at $32^{\circ} \mathrm{C}$. Clone $\mathrm{p} 4 \mathrm{U}$ from genomic library also rescued the $s p c 1^{-}$phenotypes in the same assay /data not shown!.

screening using the cDNA insert of $\mathrm{p} 2 \mathrm{~B}$ as a probe $(\mathrm{p} 5 \mathrm{~A}$; Fig. 3A). Genomic clone p5A contained a 1698-bp open reading frame (ORF) encoding a protein of 566-amino acid residues, which was named atf $1^{+}$because of its homology to human ATF-2 (see below). Very recently atf $1^{+}$ was discovered during the process of sequencing chromosome II of S. pombe (Takeda et al. 1995). Like p2B, a multi-copy plasmid pREP1-atf1 ${ }^{+}$(Fig. 3A), which expresses full-length at $f 1^{+}$under the control of thiaminerepressible $n m t 1$ promoter (Maundrell 1993), also complemented the mating defect and high-osmolarity sensitivity of $s p c 1^{-}$mutants in the presence of thiamine /data not shown), indicating that leaky expression of atf $1^{+}$ from the repressed $n m t 1$ promoter was sufficient to rescue the $s p c 1^{-}$phenotypes. Sequence analysis of the 3.9$\mathrm{kb}$ insert of $\mathrm{p} 4 \mathrm{U}$ identified two ORFs (Fig. 3B). A subclone of $\mathrm{p} 4 \mathrm{U}, \mathrm{p} 4 \mathrm{U}-1$, containing the $p c e 1^{+}$ORF encod- 
A

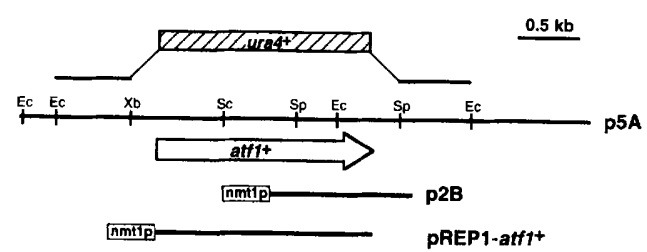

B

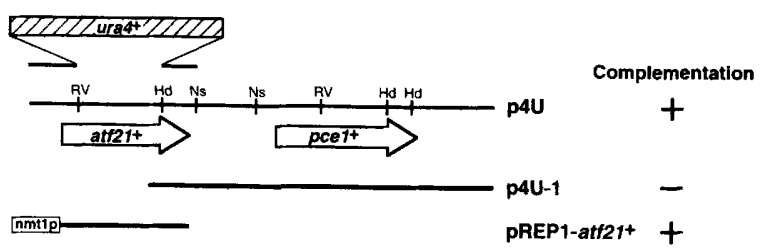

Figure 3. Restriction maps of atf $1^{+}$and atf21 $1^{+}$. (A) Clone p2B isolated from $S$. pombe cDNA library lacks the $5^{\prime}$ end of the at $f 1^{+}$open reading frame and expresses the carboxy-terminal half of the protein under the $n m t 1$ promoter (nmtlp). The atf $1^{+}$ genomic clone p5A was isolated from a $S$. pombe genomic library by hybridization screening using a $1.2-\mathrm{kb}$ insert from $\mathrm{p} 2 \mathrm{~B}$. Full-length $a t f 1^{+}$expressed from the $n m t 1$ promoter (pREPlatf $1^{+}$) also rescues $s p c 1^{-}$mating and high osmolarity defects. The plasmid construct used for atf $1^{+}$disruption with the $u r a 4^{+}$ marker is also shown. Restriction enzyme sites: (Ec) EcoRI; (Sc) SacI; $\{\mathrm{Sp})$ SphI; $(\mathrm{Xb}) \mathrm{XbaI}$. (B) Clone $\mathrm{p} 4 \mathrm{U}$ isolated from $S$. pombe genomic library was found to contain two open reading frames atf $21^{+}$and $p c e 1^{+}$that encode mRNA capping enzyme (Shuman et al. 1994). Subclone p4U-1 containing only $p c e 1^{+}$failed to rescue $s p c 1^{-}$, whereas atf $21^{+}$expressed from the $n m t 1$ promoter (pREP1-atf $21^{+}$) complemented $s p c 1^{-}$. Disruption of atf21 ${ }^{+}$was performed with the plasmid construct shown above. Restriction enzyme sites: (Hd) HindIII; (Ns) NsiI; (RV) EcoRV.

ing a mRNA capping enzyme (Shuman et al. 1994), failed to rescue $s p c 1-M 13$ (Fig. 3B). Instead, $s p c 1-M 13$ was rescued by expression of the second p4U ORF from the $n m t 1$ promoter in medium containing thiamine (Fig. 3B). The gene encoding the 355 -amino acid protein from this ORF was named atf21 ${ }^{+}$.

atf $1^{+}$and atf $21^{+}$encode transcription factors related to human ATF-2

The atf $1^{+}$and atf2 $1^{+}$genes encode $65-\mathrm{kDa}$ and $41-\mathrm{kDa}$ proteins, respectively. The deduced primary sequences of Atf 1 and Atf 21 contain a carboxy-terminal bZIP structure that consists of a DNA-binding domain composed of basic residues followed by a leucine zipper structure (Fig. 4A). A data-base search revealed that Atfl and Atf 21 are most homologous to the human ATF-2/CRE-BP1 transcription factor (Hai et al. 1989; Maekawa et al. 1989). $S$. pombe Atfl and Atf 21 show $50 \%$ and $55 \%$ identity to ATF-2 in the bZIP domains, respectively. Weak similarity is also seen in the amino-terminal domains of human ATF-2 and Atf1 (Fig. 4A), whereas, unlike ATF-2, neither of Atfl nor Atf21 have a zinc finger motif (Fig. 4B). Another cAMP response element binding protein (CREB)/ ATF-related protein in fission yeast, Pcrl, was reported recently (Watanabe and Yamamoto 1996). Pcrl is a rela-
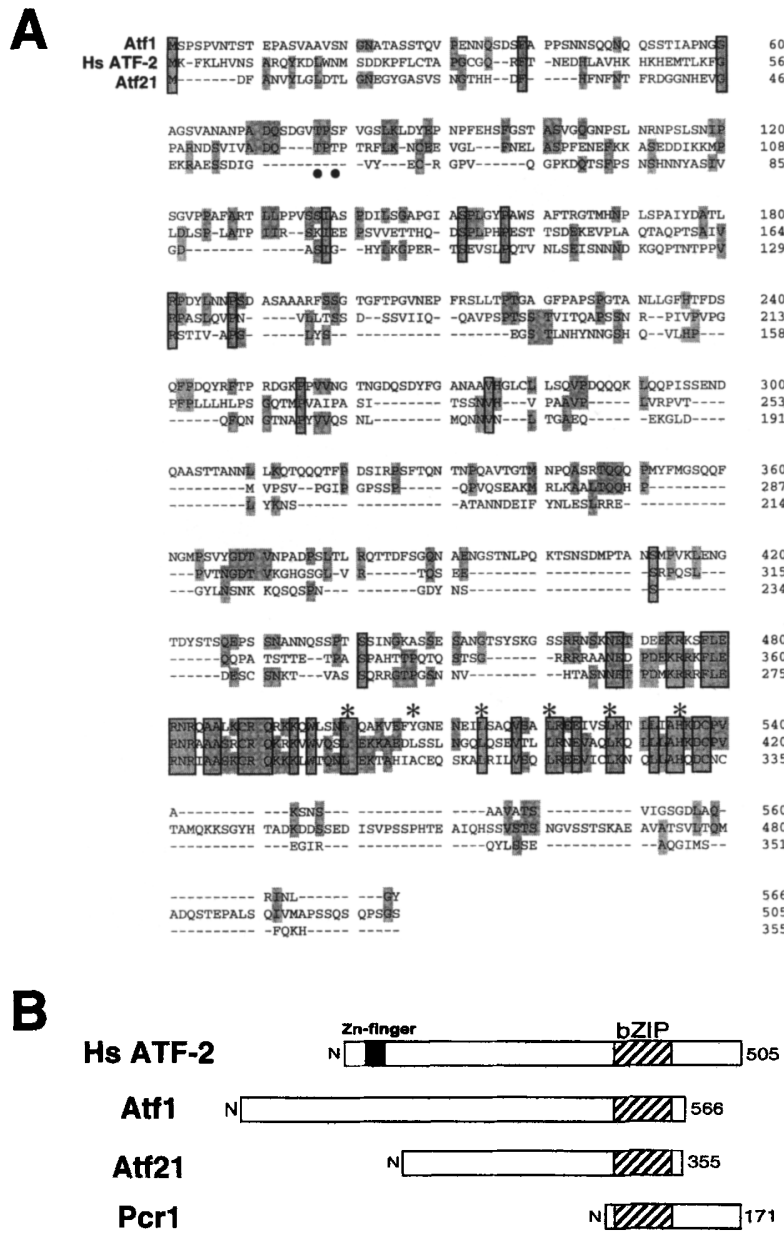

Figure 4. $(A \mid$ Comparison of predicted amino acid sequences of Atfl, human ATF-2/CRE-BP1 (Hs ATF-2) (Maekawa et al. 1989) and Atf21. Residues conserved among all three proteins are boxed and shaded residues are conserved between two of the proteins. MAPK phosphorylation sites in ATF-2 (Thr-69 and Thr-71) (Gupta et al. 1995; Livingstone et al. 1995; van Dam et al. 1995) are indicated by filled circles. Residues important for formation of the "leucine zipper" structure are marked by asterisks. GenBank accession nos.: S. pombe atf1 ${ }^{+}$, U38237; atf21 ${ }^{+}$, U51566; human ATF-2/CRE-BP1, X15875. Alignments were performed using GeneWorks software (IntelliGenetics). (B) Schematic representation of the structures of human (Hs) ATF-2 and $S$. pombe transcription factors carrying CREB/ATFlike bZIP domain, Atf1, Atf21, and Pcrl. Human ATF-2 carries a zinc finger motif in its amino-terminal domain.

tively small protein of 171-amino acid residues with a bZIP domain located near the amino terminus (Fig. 4B).

atf $1^{+}$is required for the cellular response to nitrogen starvation and sexual development

Gene disruption experiments were performed to reveal the cellular functions of Atf1 and Atf21 (see Fig. 3A,B). FACScan analyses of cells revealed that $\Delta a t f 1$ cells were highly defective in undergoing $\mathrm{G}_{1}$ arrest upon nitrogen starvation (Fig. 5A). On the other hand, $\Delta a t f 21$ cells had 
A

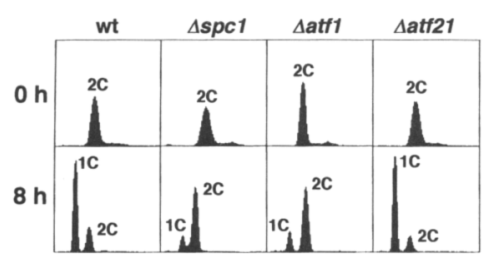

B

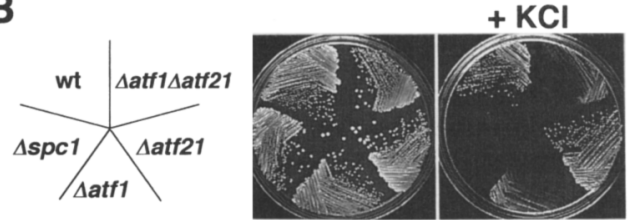

C

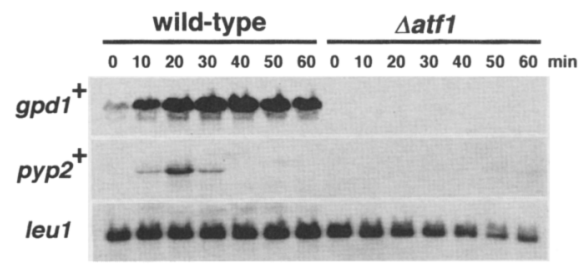

Figure 5. (A) FACScan analysis of DNA content of wild-type (wt; PR109), $\Delta$ spc1 (KS1366), $\Delta a t f 1$ (KS1497), and $\Delta a t f 21$ (KS1557) strains after nitrogen starvation. After $8 \mathrm{hr}$, only a small population of $\Delta a t f 1$ cells were arrested in $G_{1}$ with a $1 C$ DNA content in comparison with wild-type and $\Delta a t f 21$ cells. $|B|$ $\Delta a t f 1$ cells are sensitive to high osmolarity. Wild-type (wt; PR109), $\Delta$ spc1 (KS1366), $\Delta a t f 1$ (KS1497), $\Delta a t f 21$ (KS1557) and $\Delta a t f 1 \Delta a t f 21$ (KS1565) cells were streaked onto YES agar plates supplemented with or without $1 \mathrm{M} \mathrm{KCl}$, and incubated for 4 days at $32^{\circ} \mathrm{C}$. $\Delta a t f 21$ mutation showed no apparent effect on the salt sensitivity in both wild-type and $\Delta a t f 1$ backgrounds. $|C|$ Wild-type (PR109) and $\Delta a t f 1$ (KS1497) cells were grown at $30^{\circ} \mathrm{C}$ to mid-log phase in YES medium and then switched to YES + $0.6 \mathrm{M} \mathrm{KCl}$ at time 0 . Samples were taken at $10-\mathrm{min}$ intervals and processed for Northern blot analysis. Induction of $g p d 1^{+}$and pyp $2^{+} \mathrm{mRNA}$ is abolished in the $\Delta a t f 1$ cells. The leu $1^{+}$probe serves as a control.

no defect in undergoing $G_{1}$ arrest. Homothallic $\Delta a t f 1$ strains had a low mating frequency, whereas $\Delta a t f 21$ cells appeared to be normal in mating and sporulation (data not shown). $\Delta a t f 1$ and $\Delta s p c 1$ mutants were also defective in meiosis; $31 \%$ of diploid cells homozygous for $\Delta a t f 1$ and $20 \%$ of $\Delta s p c 1$ diploids performed meiosis in sporulation medium, compared to a value of $78 \%$ with wildtype diploid cells. In addition, the $\Delta a t f 1$ and $\Delta s p c 1 \mathrm{mu}$ tations suppressed meiosis induced by the temperaturesensitive pat1-114 mutation. pat $1^{+}$, also known as $\operatorname{ran} 1^{+}$, encodes a protein kinase (McLeod and Beach 1986) that regulates negatively the initiation of meiosis (Iino and Yamamoto 1985; Nurse 1985). Growth of pat1114 mutants at the restrictive temperature results in the initiation of meiosis, regardless of cell ploidy or the presence of nitrogen in the growth medium. It was found that $\Delta a t f 1$ pat1-114 and spc1-M13 pat1-114 double mutants formed colonies of mitotically dividing cells at $32^{\circ} \mathrm{C}$, whereas pat $1-114$ cells did not form colonies be- cause they underwent lethal haploid meiosis (data not shown). The $\Delta a t f 1$ conjugation defects are consistent with those recently described by Takeda and colleagues (1995). Our findings suggest that upon nitrogen starvation Spcl and Atfl function in the same pathway to promote mating and meiosis by bringing about $G_{1}$ cell cycle arrest and inducing ste $11^{+}$transcription.

\section{atf ${ }^{-}$cells are defective in the response to osmostress}

The findings described above, indicating that Atf1 and Spcl have important roles in mediating the cellular response to nitrogen starvation, prompted an examination of whether Atfl might also have a role in regulating the cellular response to osmotic stress. We found that $\Delta a t f 1$ cells grew very poorly on medium supplemented with 1 $\mathrm{M} \mathrm{KCl}$ (Fig. 5B), although the growth defect of $\Delta a t f 1$ cells was less severe than that of $\Delta s p c 1$ cells. Importantly, the osmosensitive growth caused by $\Delta s p c 1$ was not enhanced in $\Delta s p c 1 \Delta a t f 1$ double mutants (data not shown), which implies that Atf1 and Spcl function in a linear pathway. The $\Delta a t f 21$ mutation did not affect the high osmolarity sensitivity of wild-type and $\Delta a t f 1$ cells (Fig. $5 \mathrm{~B}$ ), indicating that Atf 21 does not have a major role in osmoregulation.

These findings suggested that Atfl may be involved in promoting transcription of stress response genes that are regulated by the Wisl-Spcl signal transduction pathway, such as $g p d 1^{+}, t p s 1^{+}$, and pyp $2^{+}$(Miller et al. 1995; Degols et al. 1996). Indeed, osmostress-induced expression of $g p d 1^{+}$, which encodes glycerol-3-phosphate dehydrogenase (Pidoux et al. 1990), was abolished in $\Delta a t f 1$ cells (Fig. 5 C). Expression of pyp $2^{+}$was similarly defective in $\Delta a t f 1$ cells (Fig. $5 \mathrm{C}$ ), indicating that Atf1 is a part of the negative feedback loop in which Spc1-stimulated induction of pyp2 $2^{+}$expression attenuates Spcl activity (Miller et al. 1995; Degols et al. 1996).

\section{Atf1 regulation by $S p c 1$}

Our genetic findings indicated that Atfl probably functions downstream of Spcl in the regulation of sexual differentiation and stress response; therefore, we examined the biochemical relationship between Atf1 and Spcl kinase. To facilitate analysis of Atfl protein, the chromosomal atf1 $1^{+}$gene was tagged with a sequence encoding the hemaglutinin antigen (HA) epitope and six consecutive histidine residues (see Materials and Methods). The resultant strain was indistinguishable from wild type, indicating that Atfl protein with the carboxyterminal tag was fully functional (data not shown). Atfl protein purified from unstressed wild-type cells migrated as a somewhat diffuse band with an apparent molecular mass of $\sim 85 \mathrm{kD}$ in SDS-PAGE (Fig. 6A, lane 1). When cells were stressed in a medium supplemented with 0.6 $\mathrm{M} \mathrm{KCl}$ for $10 \mathrm{~min}$, Atf 1 migrated with a reduced mobility of $\sim 90 \mathrm{kD}$ (Fig. $6 \mathrm{~A}$, lane 2). In contrast, Atf1 protein purified from a $\Delta s p c 1$ strain migrated as a less diffuse $\sim 80 \mathrm{kD}$ protein species both before and during osmostress (Fig. 6A, lanes 3,4). To determine whether the Atf 1 


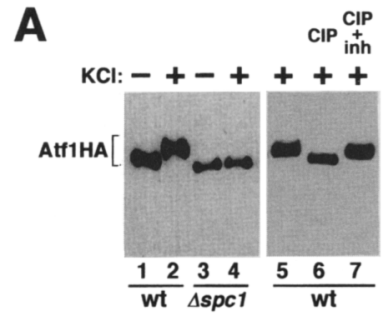

B
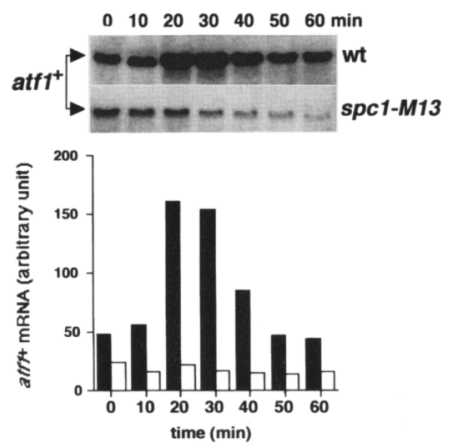

Figure 6. (A) Spcl-dependent phosphorylation of Atfl in vivo. Wild-type (KS1479, lanes 1,2,5-7) and $\Delta$ spc1 (KS1572, lanes 3,4) strains carrying a chromosomal copy of epitope tagged at $f 1^{+}$ were grown in YES medium at $30^{\circ} \mathrm{C}$, and aliquots were harvested before (lanes 1,3 ) and after osmostress in YES $+0.6 \mathrm{M} \mathrm{KCl}$ for 10 min (lanes 2,4-7). Atf1 protein tagged with HA epitopes and six His residues was purified on Ni-NTA beads and analyzed by SDS-PAGE followed by immunoblotting with anti-HA antibodies. For lanes 5-7, samples were incubated with buffer alone (lane 5), alkaline phosphatase (CIP, lane 6), or alkaline phosphatase and phosphatase inhibitors $(\mathrm{CIP}+$ inh, lane 7$)$ before electrophoresis. $(B)$ at $f 1^{+}$mRNA accumulates with osmostress in a $s p c 1^{+}$-dependent manner. Wild-type (PR 109; solid bar) and spc1-M13 (KS1147; open bar) strains were treated with $0.6 \mathrm{M} \mathrm{KCl}$ as in Fig. $5 \mathrm{C}$, and atf1 ${ }^{+}$mRNA was examined by Northern blotting. Data were quantified and calibrated using a control blot with leu $1^{+}$probe as a standard. Even before osmostress (at time 0), the level of atf1 ${ }^{+}$mRNA detected in $s p c 1^{-}$ cells was lower than wild type.

mobility shifts were caused by phosphorylation, Atf1 protein isolated from osmostressed wild-type cells was incubated with calf intestine alkaline phosphatase (CIP). After phosphatase treatment, Atfl protein migrated as a less diffuse protein species with faster mobility (Fig. 6A, lane 6), whereas no change was seen if phosphatase inhibitors were included in the incubation (Fig. 6A, lane 7). These data show that Atfl is phosphorylated in vivo in response to osmostress in a $s p c 1^{+}$-dependent manner.

As shown in Figure 6A, the amount of Atfl protein recovered from a wild-type strain was two- to threefold higher than in a $\Delta s p c 1$ strain. Therefore, we examined whether atf $1^{+}$mRNA expression was regulated by Spcl. Northern blotting analysis demonstrated that in unstressed conditions the level of atf $1^{+}$mRNA was reduced $\sim 50 \%$ in spc1-M13 cells as compared with wild type (Fig. 6B, time 0). A transient increase in the amount of $a t f 1^{+}$mRNA was observed when wild-type cells were stressed by $0.6 \mathrm{M} \mathrm{KCl}$ (Fig. $6 \mathrm{~B}$ ), whereas no increase in the amount of $a t f 1^{+}$mRNA was observed in spc1-M13 mutant cells. This finding indicates that expression of atf $1^{+}$ mRNA is also regulated by Spcl, possibly through the regulation of Atfl itself.

There is considerable evidence from studies of mammalian cells indicating that the stress-activated Jun $\mathrm{N}$-terminal kinase (JNK)/stress-activated protein kinase (SAPK) phosphorylate ATF-2 directly (Gupta et al. 1995; Livingstone et al. 1995; van Dam et al. 1995). This conclusion is supported by the detection of stable in vitro binding between JNK1 and ATF-2. Interestingly, this binding is mediated by a region of ATF- 2 that is separate from the sites of phosphorylation. We carried out experiments to evaluate whether the Spcl-dependent phosphorylation of Aftl, as established by the data shown in Figure 6A, might involve direct phosphorylation of Atfl by Spcl kinase. As a first step in this analysis, we asked whether Atfl coprecipitated with a protein kinase. These studies were facilitated by expression of glutathionine $s$-transferease (GST)-Atf1 fusion protein in $S$. pombe, which rescued both $s p c 1^{-}$and atf1- osmosensitive phenotypes (data not shown). GST-Atf1 was purified by glutathione (GSH)-Sepharose affinity precipitation and then incubated with $\mathrm{Mg}^{2+}$ and $\left[\gamma^{32} \mathrm{P}\right.$ [ATP (Fig. 7A). GST-Atf1 became highly phosphorylated in this assay, indicating that GST-Atf1 coprecipitated with a protein kinase that phosphorylates GST-Atf1 efficiently. Importantly, this phosphorylation was abolished when GST-Atfl was expressed and recovered from $\Delta s p c 1$ cells (Fig. 7A).

These findings indicate that $\mathrm{Spcl}$ or another kinase whose activity is dependent on Spc1 copurifies with and phosphorylates GST-Atf1. To distinguish between these possibilities, we first asked whether Spcl was present in the GST-Atfl samples prepared by GSH-Sepharose affinity precipitation. GST-Atf1 and unfused GST were expressed in a strain in which endogenous Spcl was tagged with the HA epitope. GST-Atfl and GST were purified by GSH-Sepharose precipitation. Spcl was detected in the GST-Atfl sample but not with GST alone (Fig. 7B). Control experiments, in which GST-Atf1 was coexpressed with HA epitope-tagged forms of Weel kinase, Niml kinase, and Cig2 B-type cyclin, confirmed that the detection of HA-tagged Spcl in GST-Atfl sample was not attributable to a nonspecific interaction between the HA epitope tag and GST-Atfl (data not shown).

These results supported the conclusion that Spc1 may be directly responsible for the phosphorylation of GSTAtfl in the GSH-Sepharose precipitates. This possibility was explored further by comparing the two-dimensional tryptic phosphopeptide map of GST-Atfl phosphorylated by its coprecipitating kinase with the map generated by direct phosphorylation of GST-Atf1 with purified Spcl kinase. The GST-Atfl isolated from $\Delta s p c 1$ cells was treated with irreversible protein kinase inhibitor $p$-flurosulfonyl-benzoyl 5 '-adenosine (FSBA) (Zoller and Taylor 1979/ to inactivate coprecipitating kinases, and then incubated with $\mathrm{Mg}^{2+}$ and $\left[\gamma^{-32} \mathrm{P}\right] \mathrm{ATP}$ together 


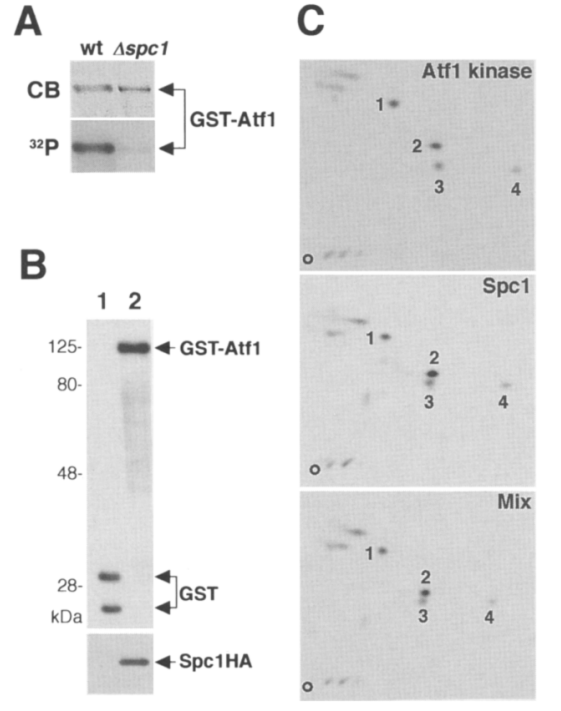

Figure 7. (A) Spc1-dependent phosphorylation of Atfl by its coprecipitating protein kinase. GST-Atf1 proteins were purified from $s p c 1^{+}(\mathrm{wt}$ KS1376) and $\Delta s p c 1$ (KS1366) strains that had been grown in $\mathrm{EMM}_{2}+0.6 \mathrm{M} \mathrm{KCl}$ for $10 \mathrm{~min}$. GST-Atfl proteins were incubated in the presence of $\mathrm{Mg}^{2+}$ and $\left[\gamma^{32} \mathrm{P} \mid \mathrm{ATP}\right.$ and subjected to SDS-PAGE. Coomassie blue (CB) staining of purified GST-Atf1 shows that approximately equal levels of GSTAtfl were recovered from the two strains. An autoradiogram of the gel $\left({ }^{32} \mathrm{P}\right)$ shows that in vitro phosphorylation of GST-Atf 1 is dependent on Spc1. Note that the phosphorylated GST-Atfl appears as a somewhat more diffuse band by CB staining, indicating that phosphorylation affects the electrophoretic mobility of GST-Atf1. (B) Physical interaction of Atfl and Spc1. GST and GST-Atfl fusion proteins expressed in KS1376 strains were precipitated using GSH-Sepharose beads. After extensive washes, proteins bound to the beads were analyzed by immunoblotting with anti-GST (upper) and anti-HA (lower) antibodies. SpclHA protein was detected in the GST-Atfl sample and not detected in the GST control sample. (C) Tryptic phosphopeptide maps of GST-Atfl proteins phosphorylated by a coprecipitating "Atfl kinase" (top), purified GST-Spc1 (middle), and a mixture of the same amount of both samples (bottom). ${ }^{32} \mathrm{P}$-labeled GST-Atfl proteins were subjected to trypsin digestion and spotted to origins shown by circles. Peptides were developed by electrophoresis at $\mathrm{pH} 1.9$ (left, anode; right, cathode) in the first dimension, which is followed by ascending chromatography in the second dimension. Because Spcl does not phosphorylate GST in vitro (data not shown), all of the phosphopeptides in the middle panel are derived from Atfl. Note that the map of the top panel is more expanded than the others because of faster ascension of the chromatography buffer.

with GST-Spcl purified from $S$. pombe. This reaction led to extensive phosphorylation of GST-Atfl, and the two-dimensional tryptic phosphopeptide pattern of GST-Atfl phosphorylated by purified Spc1 kinase was very similar to the pattern generated by analysis of GSTAtfl that had been phosphorylated by coprecipitating "Atfl kinase" (Fig. 7C). A mixing experiment confirmed that the four major phosphopeptites (labeled 1-4 in Fig. $7 \mathrm{C}$ ) in the two samples migrated with identical properties. These data provide strong evidence indicating that
Spcl is the protein kinase that coprecipitates with and phosphorylates GST-Atf 1 .

\section{Atf1 is not involved in $G_{2}-M$ cell cycle control}

Our findings indicate that Atfl 1 is a downstream target of Spcl that regulates $G_{1}$ arrest, sexual development, and the osmotic stress response. However, unlike $s p c 1^{-}$mutants that show a $G_{2}$ cell-cycle delay, $\Delta a t f 1$ cells divided at a wild-type cell length in both rich YES and minimal $\mathrm{EMM}_{2}$ media (data not shown). This observation was confirmed by the following findings. The cell lengths at which $\Delta a t f 1$ cdc25-22 double mutants and $c d c 25-22$ single mutants divided were nearly identical at $25^{\circ} \mathrm{C}$, a permissive temperature of $c d c 25-22$ mutation, which is in contrast to $c d c$ arrest phenotype exhibited by $s p c 1-M 13$ cdc25-22 double mutant grown at $25^{\circ} \mathrm{C}$ (Fig. 8A). Furthermore, the $c d c$ phenotype of a $s p c 1-M 13$ cdc25-22 wee 1-50 triple mutant at $35^{\circ} \mathrm{C}$ (Shiozaki and Russell 1995) was not rescued by overexpression of atf1 ${ }^{+}$(data not shown). These observations strongly suggest that the mitotic induction activity of Spcl is transmitted by an Atf1-independent pathway.

Bifurcation of the Spcl pathway was also implied by comparing the effects of Wis1 overproduction in $\Delta s p c 1$ and $\Delta a t f 1$ cells. Previous studies showed that $\Delta s p c 1$ cells
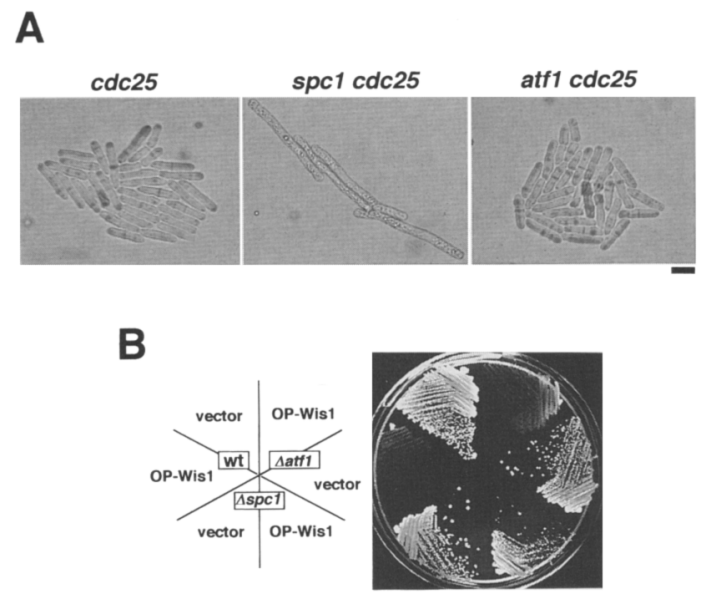

Figure 8. $(A)$ The $\Delta a t f 1$ mutation does not cause a $\mathrm{G}_{2}$ cell-cycle delay. A cdc25-22 mutant strain (GL84) was crossed with spc1$M 13$ (KS1310) or $\Delta a t f 1$ (KS1497) strains and segregants of $c d c 25$ 22, spc1-M13 $c d c 25-22$, and $\Delta a t f 1 c d c 25-22$ were grown at $25^{\circ} \mathrm{C}$. cdc25-22 and $\Delta a t f 1$ cdc25-22 double mutant cells grew well at this temperature with a moderate elongated cell morphology, whereas spc1-M13 cdc25-22 cells showed a $c d c$ arrest phenotype. Bar, $10 \mu \mathrm{m}$. (B) Phenotype of wild-type (wt; PR109), $\Delta$ spc1 (KS1366), and $\Delta a t f 1$ (KS1497) strains upon Wis1 overexpression. Strains transformed with either pREP1 vector or pREP1-wis ${ }^{+}$were streaked on an $\mathrm{EMM}_{2}$ plate without thiamine to induce the expression of Wisl from the $n m t 1$ promoter. The plate was photographed after 3 days at $30^{\circ} \mathrm{C}$. Wis 1 overproduction severely impaired growth in wild type, had a somewhat less severe effect in $\Delta a t f 1$ cells, and had very little effect on $\Delta$ spc1 cells. 
are almost completely refractive to the lethal cell lysis phenotype caused by Wisl overproduction (Shiozaki and Russell 1995). In contrast, Wisl overproduction severely decreased the size of $\Delta a t f 1$ colonies, although $\Delta a t f 1 \mathrm{col}$ onies were larger than those of wild-type cells overproducing Wisl (Fig. 8B). Microscopic examination revealed that Wisl overproduction severely deformed cell shape in $\Delta a t f 1$ cells but did not cause extensive lysis. The $\Delta a t f 21$ mutation had no affect on the toxicity of Wisl overproduction (data not shown). This result shows that the toxic effect of Spcl hyperactivation is not solely dependent on Atfl or Atf21, nor presumably on genes, such as $g p d 1^{+}$that are regulated by Atfl.

\section{Discussion}

Our results indicate that the Wis1-Spcl pathway regulates at least two different downstream targets (Fig. 9). One branch proceeds by Atfl to cause $G_{1}$ arrest and induce $s t e 11^{+}$expression in response to nitrogen limitation, and to induce expression of genes such as $g p d 1^{+}$ and pyp $2^{+}$in response to cytotoxic stress. The second

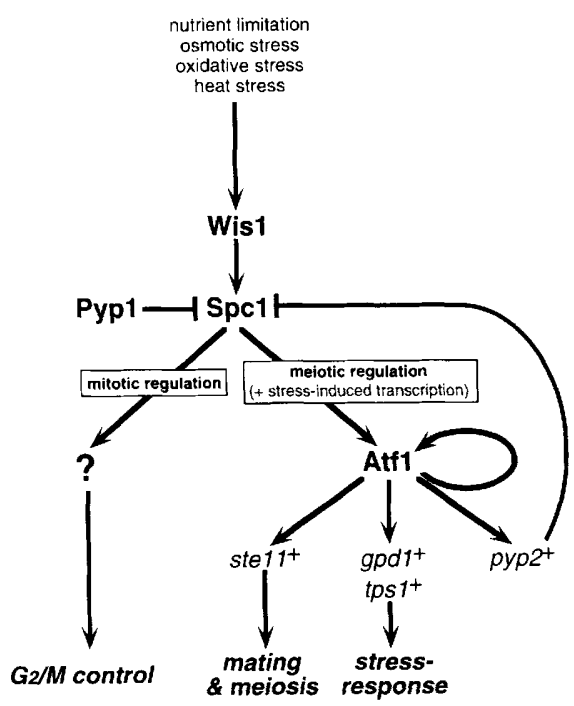

Figure 9. The Spcl stress and nutrient sensor pathway. The pathway is stimulated by various forms of environmental changes that cause cellular stress and by nitrogen limitation. The Wis1 MAP kinase homolog activates Spcl by phosphorylating Thr171 and Tyr173. Elements acting upstream of Wis 1 have not yet been identified. Spcl is inactivated by Pypl and Pyp2 tyrosine phosphatases, which dephosphorylate Tyr 173. Expression of pyp $1^{+}$is constitutive. Spcl promotes meiosis after nitrogen starvation and other stress responses through the Atfl transcription factor, which is required for induced expression of ste $11^{+}, g p d 1^{+}, t p s 1^{+}$(data not shown) and $p y p 2^{+}$. at $f 1^{+}$ expression is also stimulated by $\mathrm{Spcl}$ activation, possibly through Atfl itself, which may amplify transmitted signals. Stress-induced transcription of $p y p 2^{+}$constitutes a negative feedback loop to attenuate the $\mathrm{Spcl}$ activation. $\mathrm{Spcl}$ is expected to have additional targets to promote $\mathrm{G}_{2} / \mathrm{M}$ in the mitotic cell cycle, because unlike $\Delta s p c 1, \Delta a t f 1$ mutation does not cause a $\mathrm{G}_{2}$ delay or rescue Wisl overproduction lethality. branch regulates the onset of mitosis. Thus, the Wis1Spcl pathway bifurcates to regulate both meiosis and mitosis in response to changes in the extracellular environment.

Identification of a S. pombe ATF-2 homolog as a downstream element of the stress-activated Wis1-Spc1 kinase cascade

Two structurally related genes, at $f 1^{+}$and atf21 ${ }^{+}$, encoding bZIP transcription factors, have been identified as multicopy suppressors of the sterility and osmosensitivity of $s p c 1^{-}$cells. Atf 1 and Atf 21 are most homologous to human ATF-2/CRE-BPl (Hai et al. 1989; Maekawa et al. 1989). Evidence presented in this paper strongly indicates that Atfl is a downstream component of the Wis lSpcl pathway. First, $\Delta a t f 1$ and $\Delta s p c 1$ mutants exhibit very similar stress and sexual development deficiencies. Both mutants show osmosensitive growth and fail to induce the expression of $g p d 1^{+}$and $p y p 2^{+} . \Delta a t f 1$ and $\Delta s p c 1$ cells do not arrest in $G_{1}$ and show severe defects in sexual differentiation after nitrogen deprivation. Second, $\Delta s p c 1$ mutant phenotypes are not enhanced in $\Delta s p c 1$ $\Delta a t f 1$ double mutants. Third, overexpression of atf $1^{+}$ complements the spc1- $1^{-}$defects. Fourth, Atfl is phosphorylated upon stress in a $s p c 1^{+}$-dependent manner. Fifth, GST-Atfl coprecipitates with a kinase that phosphorylates Atf1; this kinase activity is abolished in a $s p c 1^{-}$mutant. Sixth, the tryptic phosphopeptide map derived from GST-Atfl phosphorylated by its coprecipitating kinase closely matches the pattern derived from GST-Atf1 phosphorylated by purified GST-Spcl. Finally, Spcl was detected in GST-Atfl samples purified by GSH-Sepharose precipitation.

Human ATF-2 is phosphorylated on Thr-69 and Thr71 by several kinases belonging to the extended MAP kinase family (Abdel-Hafiz et al. 1992; Gupta et al. 1995; Livingstone et al. 1995; Raingeaud et al. 1995, 1996; van Dam et al. 1995). Phosphorylation by MAP kinase increases in vitro DNA-binding activity of ATF-2, and alanine substitution of Thr- 69 and Thr- 71 abolishes the transcriptional activity of Gal4-ATF-2 fusion protein in vivo. ATF-2 activity is stimulated by UV and genotoxic agents, and bacterially produced GST-ATF- 2 fusion protein binds to stress-activated kinases JNK/SAP kinase and $\mathrm{p} 38$. The identification of Atf 1 as a downstream element of the Spcl signal transduction system further extends a similarity between yeast and mammalian stress-sensing MAP kinase pathways. Although MAP kinase cascades are conserved signal transduction modules, this is the first example that the structural similarity between the mammalian and yeast pathways has been detected to the level of downstream transcription factors. Because stress response is a basic and essential mechanism for cells to survive environmental changes, a high degree of conservation in the cellular mechanism to sense stress is perhaps not surprising.

Genes regulated by Atf1

Atfl regulates the transcription of the stress response 
gene $g p d 1^{+}$, the $p y p 2^{+}$tyrosine phosphatase gene, and the ste $11^{+}$gene that regulates the commitment to meiosis. It has also been reported that the glucose-repressible gene $f b p 1^{+}$, which encodes fructose-1,6-bisphosphatase (Vassarotti and Friesen 1985), is also regulated by at $f 1^{+}$(Takeda et al. 1995). The $f b p 1^{+}$findings are consistent with the observation that Spcl is activated in response to glucose starvation (G. Degols and P. Russell, unpubl.). In mammalian cells, ATF- 2 is implicated in the expression of transforming growth factor- $\beta 2$ (Kim et al. 1992), interferon $\beta$ (Du et al. 1993), E-selectin (De Luca et al. 1994), and c-jun (van Dam et al. 1995). More recent studies with ATF-2-deficient mice, which have severe chondrodysplasia and neurological abnormalities, have indicated that ATF-2 is required for stress-induced expression of the E-selectin gene but may not be required for expression of other genes whose promoters bind ATF-2 in vitro, including interferon $\beta$ and c-jun (Reimold et al. 1996). Like $p y p 2^{+}$, transcription of genes encoding dual specificity phosphatases that are proposed to dephosphorylate MAP kinases are induced by various forms of stress (Keyse and Emslie 1992; Ishibashi et al. 1994; Liu et al. 1995). It will be important to determine whether expression of these stress-induced MAP kinase phosphatase genes are regulated by ATF-2.

Induction of the Ste 11 transcription factor is one of the early events in the process of sexual differentiation. Ste11 expression leads to transcription of a number of genes required for conjugation and meiosis, including the mating type genes and mei2 ${ }^{+}$(Sugimoto et al. 1991). Expression of ste $11^{+}$is regulated negatively by the cAMP-dependent protein kinase (PKA) pathway (Sugimoto et al. 1991). Nitrogen deprivation from the growth medium lowers the intracellular concentration of cAMP (Mochizuki and Yamamoto 1992), which leads to derepression of ste $11^{+}$. We have shown that nitrogen starvation also induces activation of Spcl kinase and Spcl is required for ste $11^{+}$transcription. Spores are extremely resistant to all forms of stress, thus it may be significant that $S$. pombe uses a single MAP kinase pathway to regulate induction of stress response genes and to promote initiation of sexual development. Counteracting activities of stress-activated MAP kinase homologs and PKA in transcriptional regulation has also been reported in budding yeast (Schüller et al. 1994), although it is not known which transcription factors are involved.

The Wis1-Spcl-Atf1 pathway is also essential to establish a $G_{0}$-like quiescent state with nutritional deprivation. Cells lacking any component of the pathway quickly lose viability after they enter stationary phase (Warbrick and Fantes 1991; Takeda et al. 1995). This spc1 ${ }^{-}$defect is complemented by overexpression of atf $1^{+}(\mathrm{K}$. Shiozaki and P. Russell, unpubl.). An important goal of future studies will be to identify the Atf1regulated genes that are required for the asexual response to nutritional starvation.

\section{Other downstream targets of Spc1}

Unlike $\Delta s p c 1$, the $\Delta a t f 1$ mutation does not cause a $\mathrm{G}_{2}$ delay or synthetic lethality in a $c d c 25-22$ background, implying that a distinct branch of the pathway mediates the mitotic induction activity of Spc1. Little is known about this branch of the signal transduction pathway. It is possible that a protein kinase cascade extends downstream of Spcl, as p38 kinase, a mammalian homolog of $\mathrm{Spcl}$, has been implicated as an activator of MAPK-associated protein kinase-2 (Freshney et al. 1994; Rouse et al. 1994). The $c d c$ arrest phenotype of a $s p c 1-M 13 c d c 25$ 22 wee 1-50 triple mutant at $35^{\circ} \mathrm{C}$ suggests that Spcl can function independently of Wee1 and Cdc25 to regulate mitosis (Shiozaki and Russell 1995). Mutational inactivation of Mikl, a second kinase that inhibits Cdc2 (Lundgren et al. 1991), had no effect in a spc1-M13 strain, indicating that Mikl is not regulated by Spcl. The substrate of Spcl in this pathway could be another transcription factor, although Atf21 does not appear to be involved, as $\Delta$ atf 21 cells show no cell-cycle defect (data not shown). One might predict that such a transcription factor would be a high-copy suppressor of the $s p c 1^{-} c d c 25$ 22 synthetic lethal interaction, therefore experiments to identify such a gene are currently under way.

\section{Materials and methods}

Yeast strains and general techniques

Schizosaccharomyces pombe strains used in this study are listed in Table 1. They are derivatives of $972 h^{-}$and $975 h^{+}$ (Mitchison 1970). Growth media and basic genetic and biochemical techniques for fission yeast have been described /Alfa et al. 1993). Yeast extract medium YES and synthetic minimal medium $\mathrm{EMM}_{2}$ were used in growing $S$. pombe cells.

\section{Purification and detection of Spc1HA6H protein}

In strain $\mathrm{KS} 1376$ the genomic copy of $s p c 1^{+}$is tagged with a sequence encoding two copies of the HA epitope and six consecutive histidine (Shiozaki and Russell 1995). KS1376 was grown in $\mathrm{EMM}_{2}$ medium at $30^{\circ} \mathrm{C}$ to midlog phase. Cells were harvested and washed three times on a filtration apparatus with the same medium but lacking the nitrogen source $\mathrm{NH}_{4} \mathrm{Cl}$ $\left(\mathrm{EMM}_{2}-\mathrm{N}\right)$, then reinoculated in $\mathrm{EMM}_{2}-\mathrm{N}$ at $30^{\circ} \mathrm{C}$. Aliquots of cells were harvested by filtration and $\mathrm{Spc} 1 \mathrm{HA} 6 \mathrm{H}$ protein was purified on $\mathrm{Ni}^{2+}$-NTA-agarose beads (Qiagen Inc.) as described (Shiozaki and Russell 1995). Immunoblotting was performed using anti-HA (12CA5) and anti-phosphotyrosine (4G10, Upstate Biotechnology/ monoclonal antibodies.

\section{Isolation and disruption of atf $1^{+}$and atf $21^{+}$genes}

Strain KS1440 was transformed with a $S$. pombe genomic library in pUR19 (Barbet et al. 1992) and a S. pombe cDNA library constructed using the pREP3 vector in which expression of insert cDNA is regulated by the nmt1 promoter (Maundrell 1993). Transformants were plated onto $\mathrm{EMM}_{2}(3 \%$ glucose) agar plates, and then replica-plated onto $1 \%$ glucose $\mathrm{EMM}_{2}$ plates. Cells transformed with the cDNA library were plated on $\mathrm{EMM}_{2}$ supplemented with $1 \mu \mathrm{M}$ thiamine. After incubation at $26^{\circ} \mathrm{C}$ for 4 days, sporulating colonies were identified by staining with iodine vapor. Three of $\sim 70,000$ cDNA library transformants and two of $\sim 50,000$ genomic library transformants showed plasmiddependent sporulation. Recovered plasmids were analyzed by PCR and DNA hybridization. Plasmids p2B from the cDNA 
Table 1. S. pombe strains used in this study (all strains are leu 1-32 ura4-D18)

\begin{tabular}{|c|c|c|}
\hline Strains & Genotype & Source or reference \\
\hline PR109 & $h^{-}$ & Lab stock \\
\hline PR636 & $h^{90}$ & Lab stock \\
\hline CHP428 & $h^{+}$his $7-366$ ade6-M210 & C.S. Hoffman (Boston College, Chestnut Hill, MA) \\
\hline CHP429 & $h^{-}$his $7-366$ ade6-M216 & C.S. Hoffman \\
\hline GL84 & $h^{+} c d c 25-22$ & Lab stock \\
\hline LW117 & $h^{-} \operatorname{nim} 1 \mathrm{HA} 6 \mathrm{H}\left(\mathrm{ura}^{+}\right)$ & L. Wu and P. Russell, unpubl. \\
\hline FY144 & $h^{-}$pat1-114 & S.L. Forsburg (Salk Institute, La Jolla, CA) \\
\hline JM544 & $h^{-}$wis $1::$ ura4 $^{+}$ & Lab stock \\
\hline KS1172 & $h^{-}$pat1-114 spc1-M13 & This study \\
\hline KS1310 & $h^{-} s p c 1-M 13$ & Shiozaki and Russell 1995 \\
\hline KS 1366 & $h^{-} \operatorname{spc} 1:: \mathrm{ura}^{+}$ & Shiozaki and Russell 1995 \\
\hline KS1374 & $h^{+}$spc1-M13 cdc25-22 wee $1-50$ & Shiozaki and Russell 1995 \\
\hline KS 1376 & $h^{-}$spc1HA6H(ura4 $\left.{ }^{+}\right)$ & Shiozaki and Russell 1995 \\
\hline KS1440 & $h^{90} s p c 1-M 13$ & This study \\
\hline $\mathrm{OM} 1442$ & $h^{-} \mathrm{HA}^{- \text {cig2 }^{+}}$ & Mondesert et al. 1996 \\
\hline KS1479 & $h^{-}$atf1HA6H(ura4 $\left.{ }^{+}\right)$ & This study \\
\hline KS 1497 & $h^{-}$atf1::ura4 ${ }^{+}$ & This study \\
\hline KS1501 & $h^{90}$ aft $1:: u r a 4^{+}$ & This study \\
\hline KS1523 & $h^{-}$atf1::ura4 ${ }^{+}$cdc25-22 & This study \\
\hline KS1533 & $h^{-}$atf1::ura4 $4^{+}$spc1::ura4 $4^{+}$ & This study \\
\hline KS1542 & $h^{-}$atf1::ura4 $4^{+}$pat1-114 & This study \\
\hline $\mathrm{KS} 1557$ & $h^{-}$atf21::ura4 ${ }^{+}$ & This study \\
\hline KS 1562 & $h^{+}$his7-366 ade6-M210 atf1::ura4 ${ }^{+}$ & This study \\
\hline KS1565 & $h^{-}$atf $1:: u_{r a 4^{+}}$atf21::ura4 ${ }^{+}$ & This study \\
\hline KS1570 & $h^{-}$his7-366 ade6-M216 atf1::ura4 ${ }^{+}$ & This study \\
\hline $\mathrm{KS} 1572$ & $h^{-}$spc1::ura4 $4^{+}$atf1HA6H (ura4 $\left.{ }^{+}\right)$ & This study \\
\hline KS 1575 & $h^{+}$his7-366 ade6-M210 spc1::ura4 ${ }^{+}$ & This study \\
\hline $\mathrm{KS} 1578$ & $h^{-}$his7-366 ade6-M216 spc1::ura4 ${ }^{+}$ & This study \\
\hline KS1579 & $h^{90}$ atf $21:: u r a 4^{+}$ & This study \\
\hline LW1585 & $h^{-}$wee $1 H A$ & L. Wu and P. Russell, unpubl. \\
\hline
\end{tabular}

library and $\mathrm{p} 4 \mathrm{U}$ from the genomic library, which did not hy. bridize to $s p c 1^{+}$probe, were subjected to further analysis. Genomic clone of atf $1^{+}(\mathrm{p} 5 \mathrm{~A})$ was isolated from the genomic library in pUR 19 by hybridization screening using a $1.2-\mathrm{kb}$ insert of $\mathrm{p} 2 \mathrm{~B}$ as a probe. For the $a t f 1^{+}$and atf $21^{+}$gene disruption, a diploid strain constructed from CHP428 and CHP429 was transformed with the construct shown in Figure 3 carrying the $\mathrm{ura}^{+}$ marker gene (Grimm et al. 1988). Stable $\mathrm{Ura}^{+}$transformants were selected and disruption of one of $a t f 1^{+}$or atf21 $1^{+}$loci in the diploids was confirmed by Southern hybridization. After sporulation, haploid Ura ${ }^{+}$segregants were back-crossed with a wild-type strain (PR109) and used for further experiments.

\section{Northern blotting}

RNA isolation and detection of $g p d 1^{+}$and $p y p 2^{+}$mRNA by hybridization have been described (Degols et al. 1996). The ste $11^{+}$coding sequence was amplified by PCR using $S$. pombe genomic DNA as a template with a pair of primers XH-ST11 (5'-CCGCTCGAGTTCTTTAACAGCCGAGCAA-3') and ST11-NT $15^{\prime}$-TTGCGGCCGCCAAATAAATTAGAATTGGGC-3'). This PCR product was cloned into pCRII and used as a probe. The atf $1^{+}$cDNA clone $\mathrm{p} 2 \mathrm{~B}$ was used as a probe to detect atf $1^{+}$mRNA. Quantification of the results was performed using PhosphorImager (Molecular Dynamics).

\section{Meiotic assay of diploid strains}

Diploid strains were constructed by interrupted mating of wildtype CHP428 and CHP429, the isogenic $\Delta a t f 1$ derivatives
KS1562 and KS1570, and the isogenic $\Delta s p c 1$ derivatives KS1575 and KS1578. Diploids were maintained by selection for adenine prototrophy generated by complementation between ade6M210 and ade6-M216 alleles. Meiosis was induced by incubating diploid cells on sporulation medium malt extract for 2 days at $30^{\circ} \mathrm{C}$. Cells were stained by $4^{\prime}, 6$-diamidino-2-phenylindole (DAPI) and observed under the fluorescence microscope. Frequency of meiosis/sporulation was calculated according to a previously described equation (Kunitomo et al. 1995).

\section{Expression of Atf1HA6H protein}

The $\sim 0.6-\mathrm{kb}$ sequence encoding the carboxyl terminus of Atf1 (residues 363-566) was amplified by PCR with 5 ' primers NDE363 (5'-GGAATTCCATATGCCATCTGTTTACGGCGATAC$3^{\prime}$, NdeI restriction site is underlined) and 2B-NOT (5'-TAGTTTAGCGGCCGCCGTACCCTAAATTGATTCTTTGAGC-3', NotI restriction site is underlined). After digesting with $N d e \mathrm{I}$ and NotI, this fragment was cloned into pRIP42-HA6H, a derivative of pREP1-HA6H (Wu and Russell 1993) to add a carboxy-terminal tag of two copies of HA epitope and six consecutive histidine residues. The resultant plasmid was digested by PstI and NdeI and religated to eliminate the $n m t 1$ promoter sequence, then used for transformation of wild-type $S$. pombe strain (PR 109) after being linearized at the EcoRI site in at $f 1^{+}$. Stable $\mathrm{Ura}^{+}$transformants were selected and integration of the plasmid at at $f 1^{+}$locus was confirmed by Southern hybridization. The Atf $1 \mathrm{HA} 6 \mathrm{H}$ construct is expressed from at $f 1^{+}$promoter. Atf1HA6H was purified and detected by the procedures used for Spc1HA6H (see above). Phosphatase treatment of 
Atf1HA protein was performed with CIP (Boehringer Mannheim) following a published procedure (Lanker et al. 1996).

\section{Expression of GST-Atf1 fusion protein}

The $a t f 1^{+}$ORF was amplified by PCR with primers NDE-S1 (5'-GGAATTCCATATGTCCCCGTCTCCCGTCAATACTTCCAC-3', NdeI restriction site is underlined) and A1-NOT (5'TAGTTTAGCGGCCGCCTCATCTAGTACCCTAAATTGATTC-3', NotI restriction site is underlined) and cloned into the NdeI-NotI sites of pREP1-KZ, which expresses GST fusion constructs from the $n m t 1$ promoter. The resultant plasmid pREP1-KZ-atf $1^{+}$and a control plasmid pIL205 (Leatherwood et al. 1996), which expresses unfused GST from the nmt1 promoter, were used to transform strain KS1376, which expresses SpclHA6H (Shiozaki and Russell 1995). Plasmids pREP1-KZatf $^{+}$and pJL205 were also transformed into strain LW1585, which expresses Weel kinase tagged with three copies of the HA epitope; strain LW117, which expresses Niml kinase tagged with two copies of HA and six histidine residues; and strain OM1442, which expresses Cig2 B-type cyclin with a tag of three copies of HA (Mondesert et al. 1996). Expression from the nmt1 promoter was induced by thiamine depletion. GST and GSTAtfl proteins were precipitated using glutathione (GSH)-Sepharose following the procedures described previously (Shiozaki and Russell 1995/. Proteins bound to the Sepharose beads were analyzed by immunoblotting with anti-GST and anti-HA antibodies.

\section{In vitro phosphorylation of GST-Atf1}

GST-Atf1 protein from strains KS1376 [spc1HA6H(ura4 $\left.{ }^{+}\right) \mid$and $\mathrm{KS} 1366(\Delta s p c 1)$ incubated in a medium containing $0.6 \mathrm{M} \mathrm{KCl}$ for $10 \mathrm{~min}$ was recovered on GSH-Sepharose beads as described above and washed three times in KA buffer $[25 \mathrm{mM}$ Tris- $\mathrm{HCl}$ ( $\mathrm{pH}$ 7.2), $10 \mathrm{mM} \mathrm{MgCl}_{2}, 0.1 \mathrm{~mm}$ EGTA, $0.1 \mathrm{~mm} \mathrm{Na}_{3} \mathrm{VO}_{4}, 1 \mathrm{~mm}$ DTT]. The phosphorylation reaction by the coprecipitated protein kinase was performed in the same buffer containing $50 \mu \mathrm{M}$ $\left[\gamma^{32} \mathrm{P}\right]$ ATP for $10 \mathrm{~min}$ at $25^{\circ} \mathrm{C}$. For in vitro phosphorylation of Atf 1 by purified Spc1 kinase, GST-Atf 1 was purified by GSHSepharose precipitation from strain KS1366 and subjected to three successive treatments by $1 \mathrm{mM}$ FSBA at $30^{\circ} \mathrm{C}$ for $15 \mathrm{~min}$ in KA buffer without dithiothreitol (DTT). The Sepharose beads were then washed three times with KA buffer to eliminate the FSBA. GST-Spcl protein expressed in wild-type PR109 strain (Shiozaki and Russell 1995) was purified on GSH-Sepharose beads and added to FSBA-treated GST-Atfl. The mixture was incubated at $30^{\circ} \mathrm{C}$ for $20 \mathrm{~min}$ in $\mathrm{KA}$ buffer supplemented with 5 $\mathrm{mM}$ glutathione and $50 \mu \mathrm{M}\left|\gamma^{32} \mathrm{P}\right| \mathrm{ATP}$. Phosphorylation of GST-Atfl was analyzed by SDS-PAGE and the ${ }^{32} \mathrm{P}$-labeled GST-Atfl bands were excised after autoradiography. Tryptic peptide mapping was performed as described (Boyle et al. 1991) using $\mathrm{pH} 1.9$ buffer for the first dimension electrophoresis and phosphochromatography buffer for the second dimension ascending chromatography.

\section{Acknowledgments}

We thank Mitsue Shiozaki for technical assistance, Geneviève Degols and Clare McGowan for consultations, Janet Leatherwood and Stefan Lanker for technical advice, Bruce Edgar and Chris Norbury for the $S$. pombe cDNA library, Antony Carr for the $S$. pombe genomic library, and Susan Forsburg, Charlie Hoffman, and Lin Wu for strains. Gail Feiser, Ian Wilson, and Steven Reed kindly provided antibodies. K.S. was supported by a California Division-American Cancer Society, Fellowship 1-695. This research was supported by a National Institutes of Health grant awarded to P.R.

The publication costs of this article were defrayed in part by payment of page charges. This article must therefore be hereby marked "advertisement" in accordance with 18 USC section 1734 solely to indicate this fact.

\section{Note added in proof}

The atf $1^{+}$gene was also recently independently identified as gad $7^{+}$by Kanoh et al. (1996).

\section{References}

Abdel-Hafiz, H.A.-M., L.E. Heasley, J.M. Kyriakis, J. Avruch, D.J. Kroll, G.L. Johson, and J.P. Hoeffler. 1992. Activating transcription factor-2 DNA-binding activity is stimulated by phosphorylation catalyzed by $\mathrm{p} 42$ and $\mathrm{p} 54$ microtubule-associated protein kinases. Mol. Endocrinol. 6: 2079-2089.

Albertyn, J., S. Hohmann, J.M. Thevelein, and B.A. Prior. 1994. GPD1, which encodes glycerol-3-phosphate dehydrogenase, is essential for growth under osmotic stree in Saccharomy. ces cerevisiae, and its expression is regulated by high-osmolarity glycerol response pathyway. Mol. Cell. Biol. 14: 41354144.

Alessi, D.R., C. Smythe, and S.M. Keyse. 1993. The human CL100 gene encodes a Tyr/Thr-protein phosphatase which potently and specifically inactivates MAP kinase and suppresses its activation by oncogenic ras in Xenopus oocyte extracts. Oncogene 8: 2015-2020.

Alfa, C., P. Fantes, J. Hyams, M. McLeod, and E. Warbrick. 1993. Experiments with fission yeat. A laboratory course manual. Cold Spring Harbor Press, Cold Spring Harbor, NY.

Barbet, N., W.J. Muriel, and A.M. Carr. 1992. Versatile shuttle vectors and genomic libraries for use with Schizosaccharomyces prombe. Gene 114: 59-66.

Boyle, W.J., P. Van Der Geer, and T. Hunter. 1991. Phosphopeptide mapping and phosphoamino acid analysis by two-dimensional separation on thin layer cellulose plates. Methods Enzymol. 210: 110-149.

Brewster, J.L. T. de Valoir, N.D. Dwyer, E. Winter, and M.C. Gustin. 1993. An osmosensing signal transduction pathway in yeast. Science 259: 1760-1763.

Deluca, L.G., D.R. Johnson, M.Z. Whitley, T. Collins, and J.S. Pober. 1994. cAMP and tumor necrosis factor competitively regulate transcriptional activation through and nuclear factor binding to the cAMP-responsive element/activating transcription factor element of the endotherial leukocyte adhesion molecule-1 (E-selectin) promoter. I. Biol. Chem. 269: 19193-19196.

Degols, G., K. Shiozaki, and P. Russell. 1996. Activation and regulation of the Spcl stress-activated protein kinase in Schizosaccharomyces pombe. Mol. Cell. Biol. 16: 28702877.

Doi, K., A. Gartner, G. Ammerer, B. Errede, H. Shinkawa, K. Sugimoto, and K. Matsumoto. 1994. MSG5, a novel protein phosphatase promotes adaptation to pheromone response in S. cerevisiae. EMBO I. 13: 61-70.

Du, W., D. Thanos, and T. Maniatis. 1993. Mechanism of transcriptional synergism between distinct virus-inducible enhancer elements. Cell 74: 887-898.

Dunphy, W.G. 1994. The decision to enter mitosis. Trends Cell Biol. 4: 202-207.

Egel, R. 1989. Mating-type genes, meiosis, and sporulation. In 
Molecular biology of the fission yeast fed. A. Nasim, P. Young, and B.F. Johnson), pp. 31-73. Academic Press, San Diego, CA.

Freshney, N.W., L. Rawlinson, F. Guesdon, E. Jones S. Cowley, J. Hsuan, and J. Saklatvala. 1994. Interleukin-1 activates a novel protein kinase cascade that results in the phosphorylation of Hsp27. Cell 78: 1039-1049.

Grimm, C., I. Kohli, J. Murray, and K. Maundrell. 1988. Genetic engineering of Schizosaccharomyces pombe: A system for gene disruption and replacement using the ura4 gene as a selectable marker. Mol. Gen. Genet. 215: 81-86.

Gupta, S., D. Campbell, B. Dérijard, and R.J. Davis. 1995. Transcription factor ATF2 regulation by the JNK signal transduction pathway. Science 267:389-393.

Hai, T., F. Liu, W. Coukos, and M. Green. 1989. Transcription facotr ATF cDNA clones: An extensive family of leucine zipper proteins able to selectively form DNA-binding heterodimer. Genes \& Dev. 3: 2083-2090.

Han, J., J.-D. Lee, L. Bibbs, and R.J. Ulevitch. 1994. A MAP kinase targeted by endotosin and hyperosmolarity in mammalian cells. Science 265: 808-811.

Iino, Y. and M. Yamamoto. 1985. Mutants of Schizosaccharomyces pombe which sporulate in the haploid state. Mol. Gen. Genet. 198: 416-421.

Ishibashi, T., D.P. Bottaro, P. Michieli, C.A. Kelley, and S.A. Aaronson. 1994. A novel dual specificity phosphatase induced by serum stimulation and heat shock. I. Biol. Chem. 269: 29897-29902.

Kanoh, J., Y. Watanabe, M. Ohsugi, Y. Iono, and M. Yamamoto. 1996. Schizosaccaromyces pombe gad7 ${ }^{+}$encodes a phosphoprotein with a bZIP domain, which is required for proper G1 arrest and gene expression under nitrogen starvation. Genes Cells 1: 391-408.

Keyse, S.M. and E.A. Emslie. 1992. Oxidative stress and heat shock induce a human gene encoding a protein-tyrosine phosphatase. Nature 259: 644-647.

Kim, S.-J., S. Wagner, F. Liu, M.A. O'Reilly, P.D. Robbins, and M.R. Green. 1992. Retinoblastoma gene product activates expression of the human TGF- $\beta 2$ gene through transcription facotr ATF2. Nature 358: 331-334.

Kunitomo, H., A. Sugimoto, C.R.M. Wilkinson, and M. Yamamoto. 1995. Schizosaccharomyces pombe pac2 ${ }^{+}$controls the onset of sexual development via a pathway independent of the cAMP cascade. Curr. Genet. 28: 32-38.

Lanker, S., M.H. Valdivieso, and C. Wittenberg. 1996. Rapid degradation of the G1 cyclin Cln2 induced by CDK-dependent phosphorylation. Science 271: 1597-1601.

Leatherwood, I., A. Lopez-Girona, and P. Russell. 1996. Interaction of $\mathrm{Cdc} 2$ and $\mathrm{Cdcl} 8$ with a fission yeast ORC2-like protein. Nature 378: 360-363.

Lee, J.C., J.T. Laydon, P.C. McDonnell, T.F. Gallagher, S. Kumar, D. Green, D. McNulty, M.J. Blumenthal, J.R. Heys, S.W. Landvatter, J.E. Stickler, M.M. McLaughlin, I.R. Siemins, S.M. Fisher, G.P. Livi, J.R. White, J.L. Adams, and P.R. Young. 1994. A protein kinase involved in the regulation of inflammatory cytokine biosynthesis. Nature 372: 739-746.

Liu, Y., M. Gorospe, C. Yang, and N.J. Holbrook. 1995. Role of the miotogen-activated protein kinase phosphatase during the cellular response to genotoxic stress. J. Biol. Chem. 270: $8377-8380$.

Livingstone, C., G. Patel, and N. Jones. 1995. ATF-2 contains a phosphorylation-dependent transcriptional activation domain. EMBO I. 14: 1785-1797.

Lundgren, K., N. Walworht, R. Booher, M. Dembski, M. Kirschner, and D. Beach. 1991. mik1 and weel cooperate in the inhibitory tyrosine phosphorylation of cdc2. Cell 64: $1111-$
1122

Maekawa, T., H. Sakura, C. Kanei-Ishii, T. Sudo, T. Yoshimura, J. Fijisawa, M. Yoshida, and S. Ishii. 1989. Leucine zipper structure of the protein CRE-BP1 binding to the cyclic AMP response element in brain. EMBO J. 8: 2023-2028.

Maundrell, K. 1993. Thiamine-repressible expression vectors pREP and pRIP for fission yeast. Gene 123: 127-130.

McLeod, M. and D. Beach. 1986. Homology between the $\mathrm{ranl}^{+}$ gene of fission yeast and protein kinases. EMBO J. 5: 36653671 .

Millar, J.B.A., V. Buck, and M.G. Wilkinson. 1995. Pypl and Pyp2 PTPases dephosphorylate an osmosensing MAP kinase controlling cell size at division in fission yeast. Genes \& Dev. 9: 2117-2130.

Mitchison, J.M. 1970. Physiological and cytological methods for Schizosaccharomyces pombe. Methods Cell Physiol. 4: $131-$ 146.

Mochizuki, N. and M. Yamamoto. 1992. Reduction in the intracellular cAMP level triggers intiation of sexual development in fission yeast. Mol. Gen. Genet. 233: 17-24.

Mondesert, O., C. McGowan, and P. Russell. 1996. Cig2, a B-type cyclin, promotes the onset of $\mathrm{S}$ in Schizosaccharomyce pombe. Mol. Cell. Biol. 16: 1527-1533.

Nurse, P. 1985. Mutants of the fission yeast Schizosaccharomyces pombe which alter the shift between cell proliferation and sporulation. Mol. Gen. Genet. 198: 497-502.

Pidous, A.L., E.H. Fawell, and J. Armstrong. 1990. Glyerol-3phosphate dehydrogenase homologue from Schizosaccharomyce pombe. Nucleic Acids Res. 18: 7145.

Raingeaud, J., S. Gupta, J. Rogers, M. Dickens, J. Han, R. Ulevitch, and R. Davis. 1995. Pro-inflammatory cytokines and environmental stress cause p38 mitogen-activated protein kinase activation by dual phosphorylation on tyrosine and threonine. J. Biol. Chem. 270: 7420-7426.

Raingeaud, J., A.J. Whitmarsh, T. Barrett, B. Dérijard, and R.J. Davis. 1996. MKK3- and MKK6-regulated gene expression is mediated by the p38 mitogen-activated protein kinase signal transduction pathway. Mol. Cell. Biol. 16: 1247-1255.

Reimold, A., M. Grusby, B. Kosaras, J. Fries, R. Mori, S. Maniwa, I. Clauss, T. Collins, R. Sidman, M. Glimcher, and L. Glimcher. 1996. Chondrodysplasia and neurological abonormalities in ATF-2-dificient mice. Nature 379: 262-265.

Rouse, J., P. Cohen, S. Trigon, M. Morange, A. Alonso-Llamazares, D. Zamanillo, T. Hunt, and A. Nebreda. 1994. A novel Kinase cascade triggered by stress and heat shock that stimulates MAPKAP kinase-2 and phosphorylation of the small heat shock proteins. Cell 78: 1027-1037.

Schüller, C., I.L. Brewster, M.R. Alexander, M.C. Gustin, and H. Ruis. 1994. The HOG pathway controls osmotic regulation of transcription via the stress response element (STRE) of the Saccharomyces cerevisiae CTT1 gene. EMBO I. 13: 43824389.

Shiozaki, K. and P. Russell. 1995. Cell-cycle control linked to the extracellular environment by MAP kinase pathway in fission yeast. Nature 378: 739-743.

Shuman, S., Y. Liu, and B. Schwer. 1994. Covalent catalysis in nucleotidyl transfer reaction: Essential motifs in Saccharomyces cerevisiae RNA capping enzyme are conserved in Schizosaccahromyces pombe and viral capping enzymes and among polynucleotide ligases. Proc. Natl. Acad. Sci. 91: 12046-12050.

Sugimoto, A., Y. Iino, T. Maeda, Y. Watanabe, and M. Yamamoto. 1991. Schizosaccharomyces pombe stell ${ }^{+}$encodes a transcription factor with an HMG motif that is a critical regulator of sexual development. Genes \& Dev. 5: 1990-1999. 
Sun, H., C.H. Charles, L.F. Lau, and N.K. Tonks. 1993. MKP-1 (3CH134), an immediate early gene product, is a dual-specificity phosphatase that dephosphorylates MAP kinase in vivo. Cell 75: 487-493.

Takeda, T., T. Toda, K. Kominami, A. Kohnosu, M. Yanagida, and $\mathrm{N}$. Jones. 1995. Schizosaccharomyces pombe atf $1^{+}$encodes a transcription factor required for sexual development and entry into stationary phase. EMBO $/$. 14: 6193-6208.

van Dam, H., D. Wilhelm, I. Herr, A. Steffen, P. Herrlich, and P. Angel. 1995. ATF-2 is preferentially activated by stress-activated protein kinases to mediate $\mathrm{c}$-jun induction in response to genotoxic agents. EMBO $/$. 14: 1798-1811.

Varela, J.C.S., U.M. Praekelt, P.A. Meacock, R.J. Planta, and W.H. Mager. 1995. The Saccharomyces cerevisiae HSP12 gene is activated by the high-osmolarity glycerol pathway and negatively regulated by protein kinase A. Mol. Cell. Biol. 15: 6232-6245.

Vassarotti, A. and J.D. Friesen. 1985. Isolation of the fructose1,6-bisphosphatase gene of the yeast Schizosaccharomyces pombe. J. Biol. Chem. 260: 6348-6353.

Warbrick, E. and P.A. Fantes. 1991. The wis 1 protein is a dosagedependent regulator of mitosis in Schizosaccharomyces pombe. EMBO f. 10: 4291-4299.

Watanabe, Y. and m. Yamamoto. 1994. S. pombe mei2 ${ }^{+}$encodes an RNA-binding protein essential for premeiotic DNA synthesis and meiosis I, which cooperates with a novel RNA species meiRNA. Cell 78: 487-498.

- 1996. Schizosaccharomyces pombe $p c r 1^{+}$encodes a CREB/ATF protein in regulation of gene expression for sexual development. Mol. Cell. Biol. 16: 704-711.

Wu, L. and P. Russell. 1993. Niml kinase promotes mitosis by inactivating Weel tyrosine kinase. Nature 363: 738-741.

Zoller, M.J. and S.S. Taylor. 1979. Affinity labeling of the nucleotide binding site of the catalytic subunit of cAMP-dependent protein kinase using $p$-fluorosulfonyl- $\left[{ }^{14} \mathrm{C}\right]$ benzoyl $5^{\prime}$-adenosine. Identification of a modified lysine residue. $J$. Biol. Chem. 254: 8363-8368. 


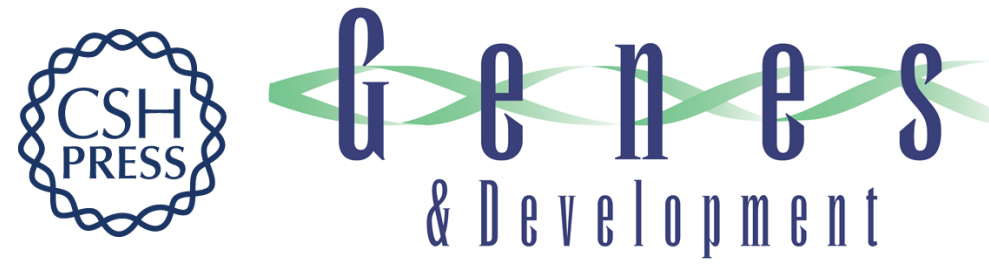

\section{Conjugation, meiosis, and the osmotic stress response are regulated by Spc1 kinase through Atf1 transcription factor in fission yeast.}

K Shiozaki and P Russell

Genes Dev. 1996, 10:

Access the most recent version at doi:10.1101/gad.10.18.2276

References This article cites 55 articles, 20 of which can be accessed free at:

http://genesdev.cshlp.org/content/10/18/2276.full.html\#ref-list-1

License

Email Alerting

Service

Receive free email alerts when new articles cite this article - sign up in the box at the top right corner of the article or click here.

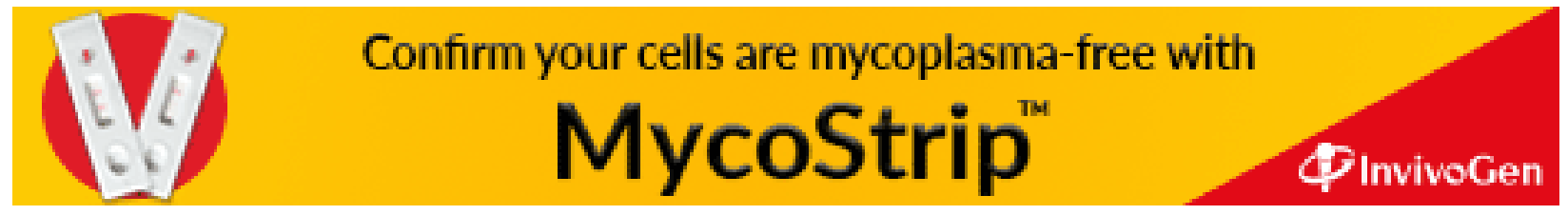

